\title{
Src kinase participates in LPS-induced activation of NADPH oxidase
}

\author{
Jennifer Check ${ }^{2}$, Christy L. Byrd ${ }^{2}$, Jade Menio ${ }^{1}$, Richard A. Rippe ${ }^{2}$, lan N. Hines ${ }^{2}$, and \\ Michael D. Wheeler ${ }^{1}$ \\ ${ }^{1}$ Department of Nutrition, East Carolina University Greenville, NC 27858 \\ ${ }^{2}$ Department of Medicine, University of North Carolina, Chapel Hill NC 27599
}

\section{Abstract}

The production of superoxide from NADPH oxidase by macrophages in response to endotoxin (LPS) is an important innate immune response, yet it is not clear how LPS signals the activation of NADPH oxidase. The hypothesis is that LPS-induced src kinase and PI3 kinase (PI3K) facilitates the activation of $\mathrm{p} 47^{\text {phox }}$, the regulatory subunit of NADPH oxidase. In mouse macrophage RAW264.7 cells, inhibition of $s r c$ tyrosine family kinases inhibited LPS-induced activation of NADPH oxidase, phosphorylation of p47phox, activation of PI3K and phosphorylation of the TLR4. Moreover, inhibition of LPS-induced increases in intracellular calcium blunted src kinase activation, PI3K association with TLR4, as well as PI3 kinase activation. These data suggest that both src kinase and PI3 kinase are involved in LPS-induced NADPH oxidase activation. Importantly, these data suggest that LPS-induced src kinase activation is critical for PI3 kinase activation as well as TLR4 phosphorylation and is dependent upon LPS-induced increase in intracellular calcium. These signaling events fill critical gaps in our understanding of LPS-induced free radical production as well as may potentially responsible for the mechanism of innate immune tolerance or desensitization caused by steroids or ethanol.

\section{Keywords}

srk kinase; PI3 kinase; superoxide; NADPH oxidase; macrophage; oxidant production; p47 phox; TLR4

\section{Introduction}

The production of superoxide from macrophages is a noted antibacterial function of innate immunity. In cell culture, bacterial endotoxins rapidly stimulate superoxide production through assembly and activation of NADPH oxidase, functionally known as the respiratory burst. Exactly how endotoxin activates macrophages to generate superoxide is still largely unknown. Specifically, the signaling mechanisms involved between the activation of the putative endotoxin receptor CD14:TLR4 and the assembly of the NADPH oxidase have not been determined.

\footnotetext{
(C) 2009 Elsevier Ltd. All rights reserved

Publisher's Disclaimer: This is a PDF file of an unedited manuscript that has been accepted for publication. As a service to our customers we are providing this early version of the manuscript. The manuscript will undergo copyediting, typesetting, and review of the resulting proof before it is published in its final citable form. Please note that during the production process errors may be discovered which could affect the content, and all legal disclaimers that apply to the journal pertain.
} 
NAPDH oxidase in macrophages is a complex of several membrane-bound proteins that are activated by the translocation of several cytoplasmic regulatory proteins. These regulatory subunits consist of $\mathrm{p} 47^{\text {phox }}$, p6 $7^{\text {phox }}$ and $\mathrm{p} 21^{\text {Rac1 }}$, a small GTP-binding protein (Ponting, 1996). Mutations in either of these regulatory subunits result in acute granulomatous disease, suggesting that NADPH oxidase is a critical component in defense against bacterial and fungal infections(Weaver and Ward, 2001).

It is the phosphorylation of $\mathrm{p} 47 \mathrm{phox}$ and its recruitment to the complex that is a key regulatory step in the production of oxidants by macrophages as well as other NADPH oxidase expressing cells, including endothelial cells and myofibroblasts. The phosphoinositide 3-kinase (PI3K) pathway has recently been identified as one of these modulators of the inflammatory response to LPS (Hebeis, Vigorito et al., 2004, Rhee, Jones et al., 2003, Li, Tupper et al., 2003);(Guha and Mackman, 2002)(Schabbauer, Tencati et al., 2004). Indeed, many studies have shown that pharmacological PI3K inactivation can inhibit TLR-mediated signaling(Fukao and Koyasu, 2003). Moreover, it was shown that PI3K was essential to the membrane recruitment of p47phox in PDGF-induced free radical production(Simon and Stutzin, 2008).

It was recently suggested that src kinase was also involved in the activation of NADPH oxidase through the phosphorylation the p47phox subunit(Chowdhury, Watkins et al., 2005). Whether or not src directly phosphorylated p47phox is not known. The src family kinases are also implicated in the signaling of cytoskeletal changes, specifically those related to phagocytosis. However, src kinases are involved in a multitude of signaling pathways and may function as an "integrator" of multiple signals in response to LPS and other stimuli in macrophages. Since, src kinase is often an activator of PI3K activity, it was hypothesized here that src kinase played an integral role in the signal transduction pathway linking LPS activation of TLR4 and NADPH oxidase activation. This report demonstrates that LPS-induced activation of src kinase is critical for LPS-induced p47phox phosphorylation, superoxide production as well as PI3 kinase activation in a mouse RAW264 macrophage cell line. Moreover, it was shown here in both RAW cells as well as Chinese hamster ovary cells expressing TLR4 that src kinase in involved in phosphorylation TLR4 following LPS stimulation. These experiments clearly demonstrate a role for src kinase in the pathway of LPS induced NADPH oxidase activity and suggest a further role in the regulation of TLR4 receptor phosphorylation which may be related to the regulation of other signaling pathways.

\section{Materials and Methods}

\section{Cells, cell culture and materials}

RAW264.7 murine macrophage cell line was maintained in Dulbecco's modified Eagle's medium supplemented with $10 \%$ FBS and antibiotics. Chinese hamster ovary (CHO) cells stably expressing CD14 were the kind gift of Dr. Douglas Golenbock (University of Massachusetts Medical School). CHO-CD14 cells were maintained in Ham's F-12 medium supplemented with 10\% FBS and antibiotics. The wild type human TLR4 and mutant TLR4 constructs in pCMV plasmid were the generous gifts from David Schwartz (Duke University). Transient transfection of LPS-responsive CHO.CD14 cells with either control pCMV, pCMV.hTLR4, or pCMV. hTLR4 plasmids $\left(2.5 \mu \mathrm{g} / 10^{5}\right.$ cells $)$ were done using Lipofectamine reagent (Gibco BRL) in a 1:3 ratio of DNA to reagent. Lipopolysaccharide (E. coli 0111:B4, Sigma, St. Loius MO) was used to stimulate both RAW264.7 cells and CHO cell lines. PP1, selective inhibitor of src family tyrosine kinases, and wortmannin, inhibitor of PI3 kinase, were used in these studies. 


\section{Immunoprecipitation and immunoblot}

Cell pellets were suspended in Tris-buffer containing $1 \%$ (vol/vol) Triton X-100 and $0.5 \%$ (wt/ vol) $\mathrm{SDS}$ at $4^{\circ} \mathrm{C}$. After centrifugation at $10,000 \times \mathrm{g}$ for $2 \mathrm{~min}$, the cell extract $(250 \mu \mathrm{g}$ protein) in a final volume of $500 \mu \mathrm{l}$ was precleared for $30 \mathrm{~min}$ with $1.0 \mu \mathrm{g}$ of nonimmune IgG. Twenty $\mu \mathrm{L}$ of a $50 \%$ slurry of Protein A/G sepharose beads (Invitrogen, Carlsbad, CA) were added, and after $30 \mathrm{~min}$ of incubation, the solution was centrifuged as above. Supernatants were incubated for $2 \mathrm{~h}$ with $20 \mu \mathrm{l}$ of antibodies against human TLR4 (Santa Cruz Biotechnologies) or p47phox (Santa Cruz Biotechnology) at $4^{\circ} \mathrm{C}$, after which $50 \mu \mathrm{l}$ of a $50 \%$ slurry of A/G beads were added, and the solution was incubated for an additional hour. After centrifugation as above, $100 \mu \mathrm{l}$ of the supernatant were added to $50 \mu \mathrm{l}$ of $2 \times$ Laemmli sample buffer $(2.3 \%$ SDS, $10 \%$ glycerol, $100 \mathrm{mM}$ dithiothreitol, and $0.37 \mathrm{M}$ Tris $\cdot \mathrm{HCl}, \mathrm{pH}$ 6.8: final concentration). The pellet was washed three times with $1 \mathrm{ml}$ of wash buffer (50 mM HEPES, pH 7.4, containing $1 \%$ Triton X-100, $0.1 \%$ SDS, $150 \mathrm{mM} \mathrm{NaCl}, 100 \mathrm{mM} \mathrm{NaF}$, and $2 \mathrm{mM}$ sodium orthovanadate) followed by boiling in $210 \mu \mathrm{l}$ of Laemmli sample buffer. Samples were subjected to SDSPAGE (6-20\% gel) and then transferred to Immobilon-P membranes for Western blotting. For Western blot analysis, cell lysates $(5-20 \mu \mathrm{g})$ were diluted in Laemmli buffer, incubated at $95^{\circ} \mathrm{C}$ for $5 \mathrm{~min}$, separated by SDS-PAGE and then transferred to Immobilon-P membranes. Membranes were blocked with 5\% BSA in TBS-Tween 20 (TBST). Immunoblots were then performed using antibodies diluted in 1\% BSA TBST. Antibodies against phospho-src (T416) (1:5000 dilution, Cell Signaling, Beverly, MA), c-src (1:1000 dilution, Santa Cruz), phosphoAkt (Ser 473) (1:1000 dilution, Cell Signaling), total Akt1/2 (1:1000 dilution, Santa Cruz), and phospho-tyr (T100) (1:2000 dilution, Cell Signaling) were used. Horseradish peroxidase conjugated secondary antibodies (Santa Cruz Biotechnology) were used to visualize immunoblots.

\section{Electrophoretic Mobility Shift Assay (EMSA)}

EMSAs were performed using ${ }^{32} \mathrm{P}$-labeled, double-stranded oligonucleotides corresponding to the NF B consensus DNA binding sequence (Santa Cruz, CA). Briefly, nuclear extracts were incubated with a ${ }^{32} \mathrm{P}$-labeled probe in binding buffer for $15 \mathrm{~min}$ at room temperature. The samples were analyzed by electrophoresis on $6 \%$ non-denaturing polyacrylamide gels in $0.5 \times$ TBE. Gels were dried and visualized by autoradiography.

\section{In vitro labeling reactions}

RAW 264.7 cells ( $\sim 90 \%$ confluence in 35 -mm dishes) were labeled with $\left[{ }^{32} \mathrm{P}\right]$ orthophosphate $(50 \mu \mathrm{Ci} / \mathrm{ml})$ in phosphate-free Dulbecco's modified Eagle's medium for $2 \mathrm{~h}$. The radioactive medium was aspirated, and cells were incubated in DMEM containing 10\% FBS for 30 min prior to exposure to LPS. Total cell extracts $(500 \mu \mathrm{g})$ were immunoprecipitated in NP-40 lysis buffer with $4 \mu \mathrm{g}$ hTLR 4 antibody or p47phox (Santa Cruz Biotechnology). Immunoprecipitates were washed three times with NP-40 lysis buffer and once with $20 \mathrm{mM}$ TrisHCl pH 7.5 with $100 \mathrm{mM} \mathrm{NaCl}$ and $1 \mathrm{mM}$ EDTA. Immunoprecipitates were separated by SDS-PAGE, transferred to PVDF membrane, and analyzed by autoradiography.

\section{Measurement of intracellular calcium concentration}

Changes in intracellular calcium concentratin $\left(\left[\mathrm{Ca}^{2+}\right]_{\mathrm{i}}\right)$ of single cells were measured fluorometrically using the calcium indicator fura 2 . Briefly, cells were plated on glass coverslips at a density of $3.0 \times 10^{5}$ cells/coverslip and were incubated in $2 \mathrm{ml}$ of HBSS containing $5 \mu \mathrm{M}$ fura 2 acetoxymethyl ester (Molecular Probes, Eugene, OR) at room temperature for $30 \mathrm{~min}$. After being loaded, cells were rinsed and placed in a measurement chamber with HBSS buffer at room temperature. A microspectrofluorometer (Photon Technology, South Brunswick, NJ) attached to an inverted microscope (Diaphot, Nikon, Japan) was used to monitor changes in intracellular calcium. Changes in fluorescent intensity of fura 
2 at excitation wavelengths of 340 and $380 \mathrm{~nm}$ and emission at $510 \mathrm{~nm}$ were recorded continuously in individual cells. The ratio of emission at 340 and $380 \mathrm{~nm}$ was determined, and the corresponding value of $\left[\mathrm{Ca}^{2+}\right]_{\mathrm{i}}$ was calculated using the relationship, $\left[\mathrm{Ca}^{2+}\right]_{i}=\mathrm{K}_{\mathrm{d}}(\mathrm{R}$ $\left.\mathrm{R}_{\min }\right) /\left(\mathrm{R}_{\max }-\mathrm{R}\right)\left(\mathrm{F}_{0} / \mathrm{F}_{\mathrm{s}}\right)$, where $\mathrm{F}_{0} / \mathrm{F}_{\mathrm{s}}$ is the ratio of fluorescent intensities in buffers containing 3 mM EGTA and $1 \mu \mathrm{M}$ ionomycin $\left(\left[\mathrm{Ca}^{2+}\right]_{\max }\right)$. $\mathrm{R}$ is the measured ratio of fluorescent intensities at excitation wavelengths of 340 and $380 \mathrm{~nm}$, and $R_{\max }$ and $R_{\min }$ are values of $R$ at $\left[\mathrm{Ca}^{2+}{ }_{\max }\right.$ and $\left[\mathrm{Ca}^{2+}\right]_{\min }$, respectively. A dissociation constant $\left(\mathrm{K}_{\mathrm{d}}\right)$ of $135 \mathrm{nM}$ was used.

\section{Superoxide production}

Raw 264.7 macrophage $\mathrm{O}_{2}^{-}$. production was measured by the superoxide dismutase (SOD)inhibitable reduction of ferricytochrome $c$ (Crapo, McCord et al., 1978). Cells were plated in 24-well tissue culture plates at $10^{6}$ cells/well and cultured at $37^{\circ} \mathrm{C}$ for $24 \mathrm{~h}$ in DMEM with $10 \%$ FBS. Supernatant was replaced with $\mathrm{m}-\mathrm{HBSS}$ and $\mathrm{Ca}^{2+}$ supplemented with ferricytochrome $c(0.8 \mathrm{mg} / \mathrm{ml}$ final concentration). Wortmannin and PP1 were added $5 \mathrm{~min}$ before LPS. The reduction of ferricytochrome $c$ was measured both in the presence and absence of SOD $(85 \mathrm{U} / \mathrm{ml})$. The difference in absorbance of ferricytochrome $c$, measured at $550 \mathrm{~nm}$, was used to calculate $\mathrm{O}_{2}^{-}$. concentration using a molar extinction coefficient of 17,500.

\section{Results}

\section{Inhibition of src kinase or PI3 kinase blunts LPS-induced superoxide production}

It has been shown in neutrophils that PI3 kinase was involved in the activation of NADPH oxidase, specifically, in the membrane association and phosphorylation of $\mathrm{p} 47^{\text {phox }}$. To test the hypothesis that src kinase and PI3K play a role in the mechanism of LPS-induced superoxide production, RAW 264.7 cells were stimulated with LPS in the presence of $100 \mathrm{nM}$ wortmannin or $5 \mathrm{nM}$ PP1 (Figure 1A). Superoxide production by RAW 264.7 cells was measured by the SOD-inhibitable reduction of cytochrome c(Crapo, McCord et al., 1978). Prior to stimulation with LPS, cells were pretreated with either $100 \mathrm{nM}$ wortmannin or $5 \mathrm{nM}$ PP1. It was observed that LPS induced a concentration-dependent increase in superoxide production in RAW264.7 cells. Pretreatment of RAW264.7 cells with $100 \mathrm{nM}$ wortmannin significantly blunted superoxide production induced by LPS. Moreover, src kinase inhibitor PP1 nearly completely inhibited LPS-induced superoxide production.

It has been shown that PI3 kinase indirectly induces the phosphorylation of $\mathrm{p} 47^{\mathrm{phox}}$, the cytoplasmic regulatory subunit of NADPH oxidase. Thus, the phosphorylation of $\mathrm{p} 47^{\text {phox }}$ was determined, following LPS exposure (Figure 1B). Cells were labeled with orthophosphate and then activated with $100 \mathrm{ng} / \mathrm{mL}$ LPS. Total p4 $7^{\text {phox }}$ was then immunoprecipitated, separated by SDS-PAGE, and phosphorylated $\mathrm{p} 47^{\mathrm{phox}}$ was then determined by autoradiograpy. A rapid increase in phosphorylated $\mathrm{p} 47^{\text {phox }}$ was observed within 15 min of LPS administration, and phosphorylation peaked $60 \mathrm{~min}$ after the addition of LPS. This rapid phosphorylation is consistent with the rapid production of superoxide from these cells. Pre-treatment of RAW264.7 cells with $100 \mathrm{nM}$ wortmannin or $5 \mathrm{nM}$ PP1 completely inhibited LPS-induced phosphorylation of $\mathrm{p} 47^{\mathrm{phox}}$ (Figure 1C). These data are consistent with the hypothesis that both src kinase and PI3 kinase are involved in the activation of NADPH oxidase following exposure to LPS.

PI3 kinase has been implicated in some cell types in LPS-induced NFkB activation (Li, Tupper et al., 2003, Pyo, Yang et al., 2003, Liu, Batkai et al., 2003). Whether PI3 kinase participated in the LPS-induced activation of NFKB was determined using nuclear extracts from RAW 264.7 cells by electrophoretic mobility shift assay. LPS $(100 \mathrm{ng} / \mathrm{ml})$ caused a significant increase in NFkB binding activity (Figure 1D). Neither wortmannin (100 nM) nor PP1 (5 nM) 
had a significant effect on LPS-induced NFkB activation. These data suggest that LPS activates the NFkB pathway independently of PI3 kinase.

\section{Src family kinase is involved in activation of PI3 kinase due to LPS}

To assess the activation of PI3K, whole cell lysates were immunoblotted for phosho-Akt, a downstream substrate for activated PI3K (Figure 2A). LPS caused a concentration-dependent increase in the phosphorylation of Akt, confirming that LPS activates PI3K (data not shown). RAW264.7 macrophages were stimulated with $100 \mathrm{ng} / \mathrm{mL} \mathrm{LPS} \mathrm{for} 30 \mathrm{~min}$ in the presence of vehicle, $100 \mathrm{nM}$ wortmannin or $5 \mathrm{nM} \mathrm{PP1}$, and phosphorylation of Akt was determined as described in the Methods. LPS caused a significant increase in PI3K activity that was significantly blocked in the presence of both PP1 and wortmannin (Figure 2A). These data support the hypothesis that LPS indeed activates PI3K, which is consistent with other previously published reports(Li, Tupper et al., 2003). Moreover, these data suggest that src kinase activates PI3K in response to LPS in RAW264.7 macrophages.

LPS-induced activation of the src kinase pathway was also determined. Src kinase phosphorylation was determined in RAW 264.7 cells treated with LPS $(100 \mathrm{ng} / \mathrm{mL})$ in the presence of $100 \mathrm{nM}$ wortmannin or $5 \mathrm{nM}$ PP1 (Figure 2B). Wortmannin had no apparent affect on LPS-induced src kinase activation whereas, PP1 nearly completely inhibited src kinase phosphorylation.

\section{LPS induced increase in intracellular calcium}

LPS stimulates a rapid increase in intracellular calcium, a known activator of src kinase. RAW264.7 cells were stimulated in the presence of PP1 and wortmannin to determine whether LPS-induced increases in intracellular calcium was up-stream or independent of src kinase and PI3 kinase (Figure 3A). Intracellular calcium was measured fluorescently using the calcium dye Fura-2. LPS caused a rapid and transient increase in calcium that was not affected by the addition of PP1 or wortmannin, supporting the hypothesis that LPS-induced calcium signaling is either up-stream or independent of src kinase and PI3 kinase.

To address whether calcium release is involved in the activation of src kinase and potentially explain src kinase activation, RAW 264.7 cells were stimulated with LPS in the presence of $50 \mathrm{nM}$ BAPTA, an intracellular calcium chelator (Figure 3B). Phosphorylated src kinase and phosphorylated Pyk2, a src kinase substrate, were measured by Western blot. Src kinase and Pyk2 were phophorylated 30 min after LPS exposure. However, in the presence of $50 \mathrm{nM}$ BAPTA, LPS-induced src kinase phosphorylation was blunted significantly. Additionally, pyk2 phosphorylation was also inhibited in the presence of BAPTA.

\section{LPS causes phosphorylation of TLR4}

We showed that PI3K directly interacts with activated TLR4 (Figure 4A). Raw cells were stimulated with $100 \mathrm{ng} / \mathrm{mL}$ LPS for 1 hour. Lysate was immune-precipitated using antibodies against TLR4 or PI3K and subsequently immunoblotted using antibodies against TLR4 and PI3K. In lysates stimulated with LPS, PI3K immunoprecipitated with TLR4, suggesting an interaction stimulated by LPS.

This interaction presumably is facilitated by src kinase and likely plays a role in the activation of PI3K. It was hypothesized that the intracellular region of TLR4 would be phosphorylated in response to LPS to test this hypothesis, RAW264.7 macrophages were stimulated with 100 $\mathrm{ng} / \mathrm{mL}$ LPS up to $1 \mathrm{~h}$. The phosphorylation of TLR4 was determined first by in vivo ${ }^{32} \mathrm{P}-\mathrm{ATP}$ labeling assay (Figure 4B). Cells were labeled with ${ }^{32} \mathrm{P}$-orthophosphate prior to activation by LPS. At several times after the addition of LPS, whole cell extracts were immunoprecipitated using an antibody against mouse TLR4, and immunoprecipitates were separated by Western 
blot analysis, and labeling was determined by autoradiography. A transient increase in TLR4 phosphorylation occurred with a peak increase at $30 \mathrm{~min}$ after LPS. Interestingly, this timedependent increase is consistent with the activation of PI3 kinase caused by LPS.

In separate experiments, RAW264.7 macrophage cell extracts were again immunoprecipitated using the mouse TLR4 antibody as described above. Immunoprecipitates were separated and then immunoblotted using anti-phosphotyrosine antibodies (Figure 4C). As in the labeling experiments, a transient increase in tyrosine phosphorylation of TLR4 was observed between 15 and 30 min after LPS. Throughout the time course of these experiments, however, the levels of TLR4 expression was not altered. These experiments support the hypothesis that LPS causes a time-dependent increase in TLR4 phosphorylation that is consistent with the kinetics of other LPS-induced signaling pathways including PI3K. These data corroborate other recent findings that also report that TLR4 can be phosphorylated in response to LPS(Chen, Zuraw et al., 2003).

\section{Phosphorylation of TLR4 mediates PI3 kinase activation}

To address the mechanism of TLR4 phosphorylation caused by LPS and its role in PI3K activation, LPS-responsive Chinese hamster ovary cells stably expressing CD14 (CHO.CD14) were stimulated with LPS (Figure 5). Phosphorylation of src kinase and PI3K was slightly induced, as expected since CHO cells express low levels of TLR4. However, when CHO.CD14 cells were transiently transfected with plasmid containing wildtype mouse TLR4, LPS (100 $\mathrm{ng} / \mathrm{mL}$ ) caused a significant increase in the phosphorylation of both src kinase and Akt, compared to cells transfected with control plasmid (Figure 5A and B). Inhibition of PI3K with wortmannin blocked LPS-induced phosphorylation of Akt but failed to block the phosphorylation of src (Figure 5A). Inhibition of src kinase using $5 \mathrm{nM}$ PP1, completely inhibited LPS-induced src kinase activation and PI3 kinase activation (Figure 5B). These data for the first time suggest that LPS-induced PI3 kinase activation is dependent upon the activation of src kinase.

Using the same approach, it was shown in CHO.CD14 cells expressing human TLR4 that LPS caused phosphorylation of TLR4 (Figure 5C and D). Wortmannin inhibited LPS-induced PI3K activity but had no effect on the src kinase activity nor the phosphorylation of TLR4. Importantly, the phosphorylation of TLR4 caused by LPS was completely inhibited by PP1. These data support the hypothesis that src kinase is involved in LPS-induced phosphorylation of TLR4 and activation of PI3K, and that TLR phoshphorylation may be required for subsequent activation of PI3K.

\section{Discussion}

\section{Src kinase and PI3 kinase couples LPS: TLR4 signaling to NADPH oxidase}

One important point of this study is the finding that the src kinase/ PI3K pathway connects LPS induced CD14:TLR4 activation with NADPH oxidase production of superoxide in macrophages. It has long been known that LPS induces superoxide production in macrophages, and that this phenomenon is a classical response in phagocyte "respiratory burst." However, the signaling pathways involved in this event have not been fully described. Pontin and others have demonstrated that phosphotidylinositols activate and induce the membrane localization of the p47 ${ }^{\text {phox }}$ subunit of NADPH oxidase(Chen, Powell et al., 2003), supporting the conclusion that PI3 kinase is important in NADPH oxidase activation. Moreover, it was shown that src kinase was involved in the direct phosphorylation of p47phox in lung endothelial cells under hyperoxic conditions(Chowdhury, Watkins et al., 2005). 
Though src kinase and PI3 kinase have been implicated in p47phox activation, we demonstrate here that both are required for LPS-induced free radical production in macrophages. Another key point of our findings is that LPS induced PI3K activation is actually dependent upon src kinase activity. Inhibition of src kinase with PP1 completely blocked LPS induced PI3K activity. In other words, src kinase activation appears to be upstream and required for PI3 kinase activity stimulated by LPS. Whether or not src kinase directly stimulates PI3K or whether other signaling intermediates exist is not known.

\section{Src kinase is involved in the phosphoryation of TLR4}

Several reports have demonstrated that LPS activates src kinases in RAW macrophages and primary macrophages(Leu, Charoenfuprasert et al., 2006, Smolinska, Horwood et al., 2008). These findings are consistent with reports that have demonstrated that src family kinases were activated by LPS in a variety of other cell types (Napolitani, Bortoletto et al., 2003, Fang, Pengal et al., 2004, Orlicek, Hanke et al., 1999, Williams and Ridley, 2000). The mechanism by which TLR4 initiates signaling is not completely understood.

The MyD88 dependent pathway seems to involve a direct interaction with TLR4 and recruits a number of other downstream signaling molecules including IRAK. Importantly, LPS causes a rapid interaction among the adapter protein MyD88, TLR4 and the p85 subunit of PI3K (Laird, Rhee et al., 2009). We also showed that LPS caused an interaction between TLR4 and p85 PI3K subunit; however, no interactions between the MyD88 adaptor and p85 were observed (data not shown). The hypothesis is that this interaction with TLR4 is facilitated by a rapid phosphorylation of the intracellular region of the receptor. This hypothesis is based on the recent report that TLR4 was phosphorylated via an unidentified tyrosine kinase(Chen, Zuraw et al., 2003). Vogel demonstrated that mouse TLR4 signaling was dependent upon its phosphorylation at $\mathrm{T} 712$, the tyrosine mutation responsible for $\mathrm{C} 3 \mathrm{H}-\mathrm{HeJ}$ mouse endotoxin unresponsiveness(Medvedev, Piao et al., 2007). Indeed, it is demonstrated here that TLR4 is phosphorylated transiently following LPS challenge (Figure).

A number of macrophage receptors including FcgRI and FcgRIIIa are phosphorylated by the membrane associated Src family tyrosine kinases(Cooney, Phee et al., 2001). Inhibition of src kinase blunted LPS receptor phosphorylation suggesting that src kinase is indeed involved in the potentiation of the TLR4 signal. These are the first data demonstrating that src kinase plays this important role in TLR4 signaling in macrophages as wells as in CHO cells overexpressing CD14 and TLR4. Inhibition of PI3K has no effect on TLR4 phosphorylation in both RAW cells and in $\mathrm{CHO}$ cells, suggesting again that PI3K is a downstream event from src kinase activation.

An unanswered question is whether specific phosphorylation occurs and whether it is important for PI3 kinase binding and activation, as suggested by Vogel(Medvedev, Piao et al., 2007). An intriguing experiment would be whether the expression of mutant TLR4 was capable of stimulating either src kinase or PI3K to ultimately address the cooperation of src and PI3K in the phosphorylation of TLR4. The important contribution here is that inhibition of src kinase blunted LPS-induced phoshorylation of TLR4 and downstream activation of PI3K (Figure).

\section{Src kinase activation by LPS is dependent upon increases in intracellular calcium}

The purpose of src kinase in LPS signaling is not clear, especially since src kinases play an important role in cytoskeletal changes and focal adhesion assembly, such as the LPS-induced assembly of CD11b/CD18 adhesion complex(Wright and Jong, 1986). Recently, it was shown that LPS can induce the phosphorylation of paxillin, a known downstream target of the src tyrosine kinase family involved in cytoskeletal structure(Hazeki, Masuda et al., 2003). Thus, 
a role for src family kinases and PI3K in LPS-induced phagocytosis is reasonable since cytoskeletal changes are typically coupled with the "respiratory burst" via NADPH oxidase.

How src kinase is initially activiated by TLR4 is also unknown. As for the case of TLR2, ligands stimulate the release of $\mathrm{Ca} 2+$ from intracellular stores, activating c-Src, which leads to TLR2 phosphorylation and PI3K recruitment(Chun and Prince, 2006). These data suggest a similar mechanism explaining TLR4 activation of src in RAW cells. Clearly, LPS stimulates the rapid and transient release of $\mathrm{Ca} 2+$ which is blunted strongly by BAPTA chelation. Inhibition of the increase in intracellular calcium nearly completely blocked the LPS induced activation of src and PI3K. Previous studies suggest that intracellular calcium was essential in LPS induced superoxide production but not NFkB activation. These data suggest that calcium participates as a second messenger in LPS-mediated src kinase activation, which is an integral component of LPS-induced NADPH oxidase activation.

In conclusion, it is demonstrated here that both src family tyrosine kinases and PI3K play an important role in LPS-induced superoxide production, the phosphorylation of TLR4 is necessary for its association with and activation of PI3 kinase, src kinase is responsible for the phosphorylation of the TLR4, and that the increase in intracellular calcium seems to be important for src kinase activation. Moreover, it appears that this pathway is distinct from that of NFKB signaling since inhibition of either src or PI3K had no effect on NFKB DNA binding activity. Whether the pathways are distinctly different from the point of initiation at TLR4 activation or whether the pathways diverge at some point downstream at MyD88, for example, is not clear. The important question of how src family tyrosine kinases are activated in response to LPS remains, but highlights, a critical gap in our understanding, given the various functions of src family tyrosine kinases in cytoskeletal changes, gene regulation, and lymphoctyte and monocyte differentiation. Importantly, the PI3 kinase pathway represents a unique target for therapy since it appears to be distinct from LPS-induced NFkB pathway. Moreover, NADPH oxidase has been implicated in a number of chronic diseases such as arthritis, liver diseases, and vascular disease.

\section{References}

Chen LY, Zuraw BL, Zhao M, Liu FT, Huang S, Pan ZK. Involvement of protein tyrosine kinase in Tolllike receptor 4-mediated NF-kappa B activation in human peripheral blood monocytes. Am. J. Physiol. Lung Cell. Mol. Physiol 2003;4:L607-13. [PubMed: 12495941]

Chen Q, Powell DW, Rane MJ, Singh S, Butt W, Klein JB, McLeish KR. Akt phosphorylates p47phox and mediates respiratory burst activity in human neutrophils. J. Immunol 2003;10:5302-5308. [PubMed: 12734380]

Chowdhury AK, Watkins T, Parinandi NL, Saatian B, Kleinberg ME, Usatyuk PV, Natarajan V. Srcmediated tyrosine phosphorylation of $\mathrm{p} 47 \mathrm{phox}$ in hyperoxia-induced activation of NADPH oxidase and generation of reactive oxygen species in lung endothelial cells. J. Biol. Chem 2005;21:2070020711. [PubMed: 15774483]

Chun J, Prince A. Activation of Ca2+-dependent signaling by TLR2. J. Immunol 2006;2:1330-1337. [PubMed: 16818794]

Cooney DS, Phee H, Jacob A, Coggeshall KM. Signal transduction by human-restricted Fc gamma RIIa involves three distinct cytoplasmic kinase families leading to phagocytosis. J. Immunol 2001;2:844854. [PubMed: 11441091]

Crapo JD, McCord JM, Fridovich I. Preparation and assay of superoxide dismutases. Methods Enzymol 1978:382-393. [PubMed: 362127]

Fang H, Pengal RA, Cao X, Ganesan LP, Wewers MD, Marsh CB, Tridandapani S. Lipopolysaccharideinduced macrophage inflammatory response is regulated by SHIP. J. Immunol 2004;1:360-366. [PubMed: 15210794]

Fukao T, Koyasu S. PI3K and negative regulation of TLR signaling. Trends Immunol 2003;7:358-363. [PubMed: 12860525] 
Guha M, Mackman N. The phosphatidylinositol 3-kinase-Akt pathway limits lipopolysaccharide activation of signaling pathways and expression of inflammatory mediators in human monocytic cells. J. Biol. Chem 2002;35:32124-32132. [PubMed: 12052830]

Hazeki K, Masuda N, Funami K, Sukenobu N, Matsumoto M, Akira S, Takeda K, Seya T, Hazeki O. Toll-like receptor-mediated tyrosine phosphorylation of paxillin via MyD88-dependent and independent pathways. Eur. J. Immunol 2003;3:740-747. [PubMed: 12616494]

Hebeis BJ, Vigorito E, Turner M. The p110delta subunit of phosphoinositide 3-kinase is required for the lipopolysaccharide response of mouse B cells. Biochem. Soc. Trans 2004;(Pt 5):789-791. [PubMed: 15494016]

Laird MH, Rhee SH, Perkins DJ, Medvedev AE, Piao W, Fenton MJ, Vogel SN. TLR4/MyD88/PI3K interactions regulate TLR4 signaling. J. Leukoc. Biol. 2009

Leu TH, Charoenfuprasert S, Yen CK, Fan CW, Maa MC. Lipopolysaccharide-induced c-Src expression plays a role in nitric oxide and TNFalpha secretion in macrophages. Mol. Immunol 2006;4:308-316. [PubMed: 15869794]

Li X, Tupper JC, Bannerman DD, Winn RK, Rhodes CJ, Harlan JM. Phosphoinositide 3 kinase mediates Toll-like receptor 4-induced activation of NF-kappa B in endothelial cells. Infect. Immun 2003;8:4414-4420. [PubMed: 12874320]

Liu J, Batkai S, Pacher P, Harvey-White J, Wagner JA, Cravatt BF, Gao B, Kunos G. Lipopolysaccharide induces anandamide synthesis in macrophages via CD14/MAPK/phosphoinositide 3-kinase/NFkappaB independently of platelet-activating factor. J. Biol. Chem 2003;45:45034-45039. [PubMed: 12949078]

Medvedev AE, Piao W, Shoenfelt J, Rhee SH, Chen H, Basu S, Wahl LM, Fenton MJ, Vogel SN. Role of TLR4 tyrosine phosphorylation in signal transduction and endotoxin tolerance. J. Biol. Chem 2007;22:16042-16053. [PubMed: 17392283]

Napolitani G, Bortoletto N, Racioppi L, Lanzavecchia A, D'Oro U. Activation of src-family tyrosine kinases by LPS regulates cytokine production in dendritic cells by controlling AP-1 formation. Eur. J. Immunol 2003;10:2832-2841. [PubMed: 14515267]

Orlicek SL, Hanke JH, English BK. The src family-selective tyrosine kinase inhibitor PP1 blocks LPS and IFN-gamma-mediated TNF and iNOS production in murine macrophages. Shock 1999;5:350354. [PubMed: 10565609]

Ponting CP. Novel domains in NADPH oxidase subunits, sorting nexins, and PtdIns 3-kinases: binding partners of SH3 domains? Protein Sci 1996;11:2353-2357. [PubMed: 8931154]

Pyo H, Yang MS, Jou I, Joe EH. Wortmannin enhances lipopolysaccharide-induced inducible nitric oxide synthase expression in microglia in the presence of astrocytes in rats. Neurosci. Lett 2003;3:141144. [PubMed: 12853104]

Rhee SH, Jones BW, Toshchakov V, Vogel SN, Fenton MJ. Toll-like receptors 2 and 4 activate STAT1 serine phosphorylation by distinct mechanisms in macrophages. J. Biol. Chem 2003;25:2250622512. [PubMed: 12686553]

Schabbauer G, Tencati M, Pedersen B, Pawlinski R, Mackman N. PI3K-Akt pathway suppresses coagulation and inflammation in endotoxemic mice. Arterioscler. Thromb. Vasc. Biol 2004;10:19631969. [PubMed: 15319270]

Simon F, Stutzin A. Protein kinase C-mediated phosphorylation of p47 phox modulates platelet-derived growth factor-induced $\mathrm{H} 2 \mathrm{O} 2$ generation and cell proliferation in human umbilical vein endothelial cells. Endothelium 2008;4:175-188. [PubMed: 18663621]

Smolinska MJ, Horwood NJ, Page TH, Smallie T, Foxwell BM. Chemical inhibition of Src family kinases affects major LPS-activated pathways in primary human macrophages. Mol. Immunol 2008;4:9901000. [PubMed: 17875324]

Weaver SA, Ward SG. Phosphoinositide 3-kinases in the gut: a link between inflammation and cancer? Trends Mol. Med 2001;10:455-462. [PubMed: 11597520]

Williams LM, Ridley AJ. Lipopolysaccharide induces actin reorganization and tyrosine phosphorylation of Pyk2 and paxillin in monocytes and macrophages. J. Immunol 2000;4:2028-2036. [PubMed: 10657655]

Wright SD, Jong MT. Adhesion-promoting receptors on human macrophages recognize Escherichia coli by binding to lipopolysaccharide. J. Exp. Med 1986;6:1876-1888. [PubMed: 3537192] 
A

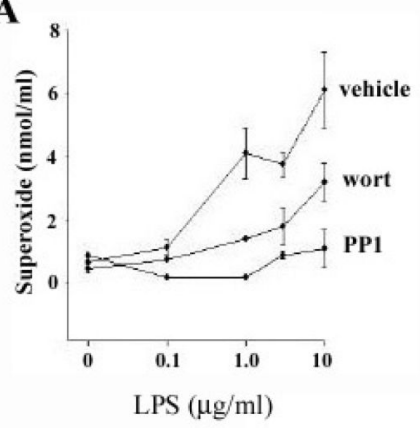

B

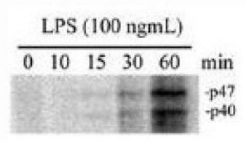

C

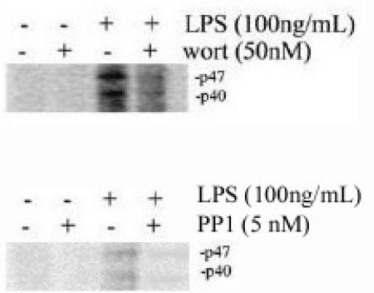

D

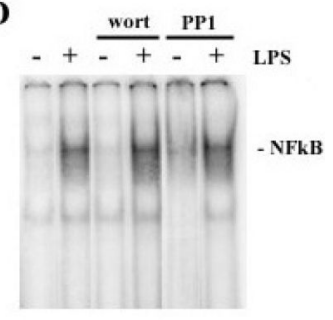

Figure 1. Inhibition of PI3 kinase and src kinase blunts LPS-induced superoxide production and p47 ${ }^{\text {phox }}$ phosphorylation

(A) RAW 264.7 macrophages were incubated in the presence of $100 \mathrm{nM}$ wortmannin or vehicle and stimulated with LPS. Cells were stimulated with LPS $(0,0.1,1.0$ and $10 \mu \mathrm{g} / \mathrm{ml})$ for $30 \mathrm{~min}$. Superoxide production was measured in the supernatant by the reduction of cytochrome c. Data are expressed as mean \pm SEM for 3 or more experiments. (B) Phosphorylation of $\mathrm{p} 47^{\mathrm{phox}}$ was determined by in vivo kinase labeling with ${ }^{32} \mathrm{P}$. Cells were treated with LPS $(100 \mathrm{ng} / \mathrm{mL})$ for 10, 15, 30 and $60 \mathrm{~min}$. Lysates were immunoprecipited with antibodies against p47, and separated by SDS-PAGE and visualized by autoradiography. (C) Cells were stimulated with $100 \mathrm{ng} / \mathrm{mL}$ LPS for $30 \mathrm{~min}$ in the presence of saline, wortmanin or PP1. Data are representative. (D) Nuclear extracts from RAW264.7 cells stimulated with $100 \mathrm{ng} / \mathrm{mL}$ LPS in the presence of PP1 or wortmannin were used to evaluate NFkB activity by EMSA as described in the Materials and Methods. Data are expressed as mean \pm SEM for 3 or more experiments 


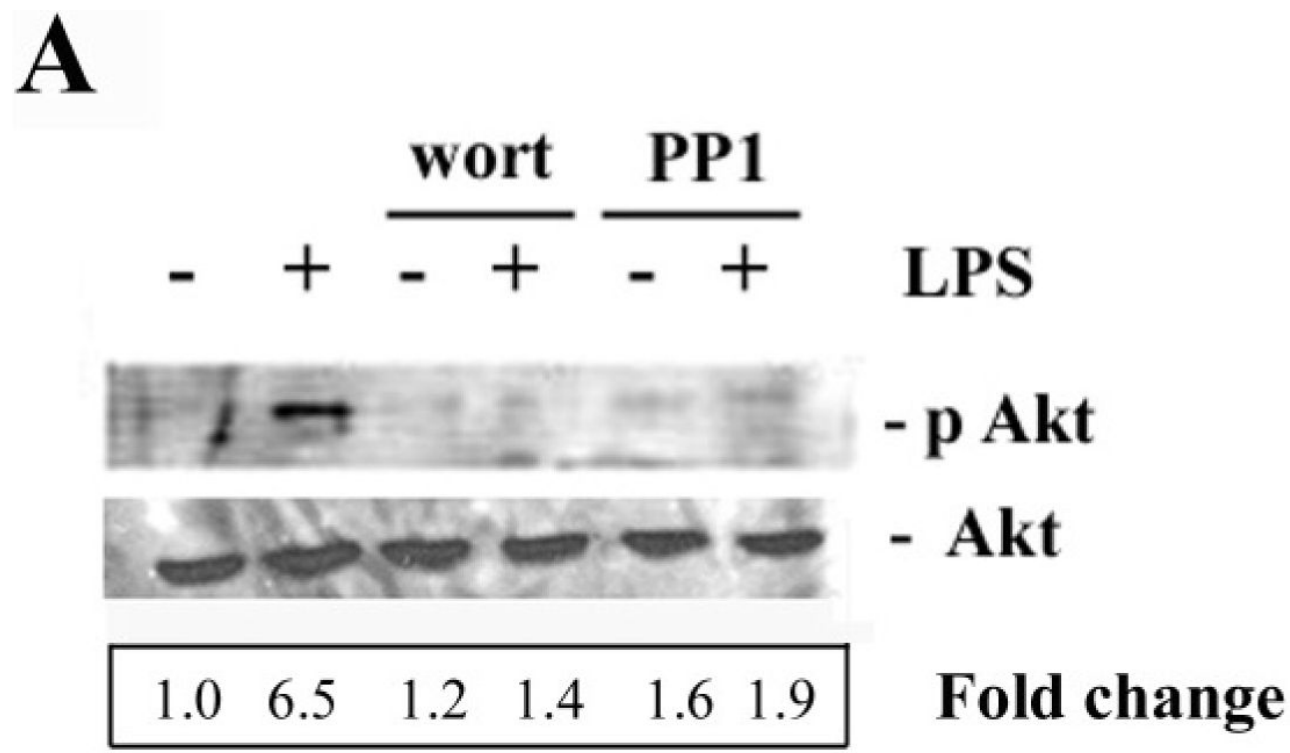

B

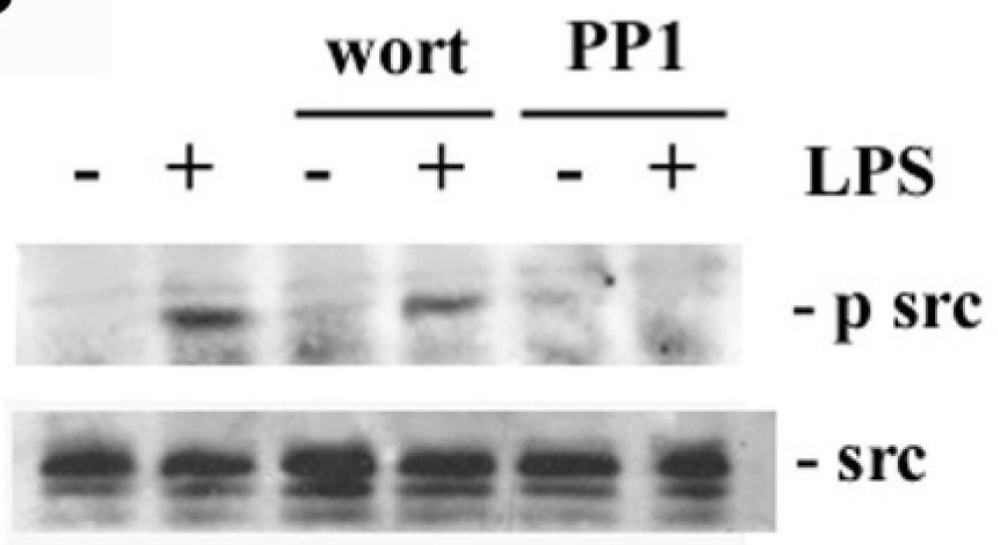

\section{\begin{tabular}{llllll|ll}
1.0 & 8.1 & 1.3 & 6.9 & 1.9 & 1.4 & Fold change
\end{tabular}}

Figure 2. Src kinase is involved in LPS-induced PI3 activity in macrophages

(A) RAW 264.7 macrophages were incubated in the presence of PP1 $(5 \mathrm{nM})$, wortmannin (100 $\mathrm{nM}$ ) or vehicle and stimulated with LPS ( $100 \mathrm{ng} / \mathrm{ml}$ ). After $30 \mathrm{~min}$, cell lysates were separated by SDS-PAGE and immunoblotted against phospho-AKT. Relative amount of phosph-Akt to total Akt expression is shown. Data is relative to control levels and are expressed as fold change. (B) RAW 264.7 macrophages were stimulated with $100 \mathrm{ng} / \mathrm{mL}$ LPS in the presence of saline, $5 \mathrm{nM}$ PP1 or $100 \mathrm{nM}$ wortmannin. Lysates were separated by SDS-PAGE and immunoblotted with antibodies against phospho- src kinase or total src kinase. Relative amount of phosph-src to total src expression is shown. Data is relative to control levels and are expressed as fold change. 
A

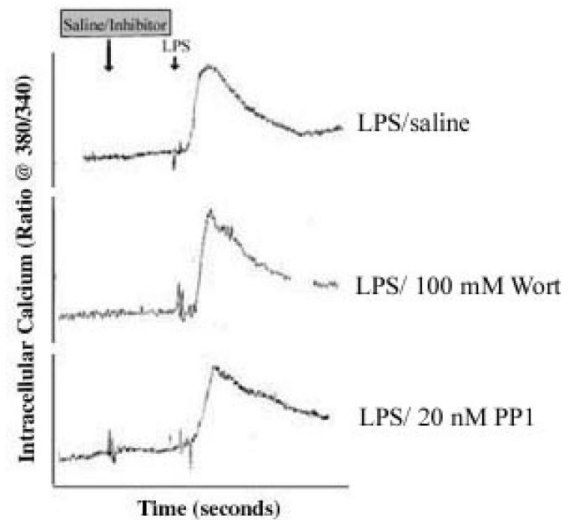

B
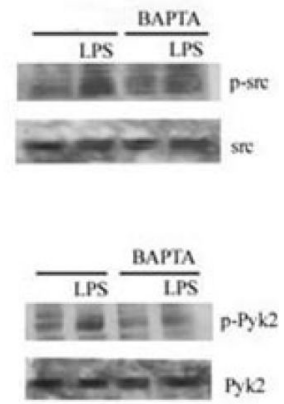

Figure 3. Chelation of intracellular calcium blunts LPS-induced src kinase blunts

(A) RAW 264.7 macrophages were incubated in the presence of vehicle, $100 \mathrm{nM}$ wortmannin or $5 \mathrm{nM}$ PP1 and stimulated with LPS. Intracellular calcium was determined by single-cell fluorescent microscopy using the calcium indicator Fura-2 as described in the Materials and Methods. Each trace is the average of 20-30 cells per experiment and is representative of three to five experiments. (B) RAW 264.7 macrophages were stimulated with $100 \mathrm{ng} / \mathrm{mL}$ LPS in the presence of saline, $50 \mathrm{nM}$ BAPTA, a calcium chelator. Lysates were separated by SDSPAGE and immunoblotted with antibodies against phospho- src kinase, total src kinase, phosphor-Pyk2 and total Pyk2. 

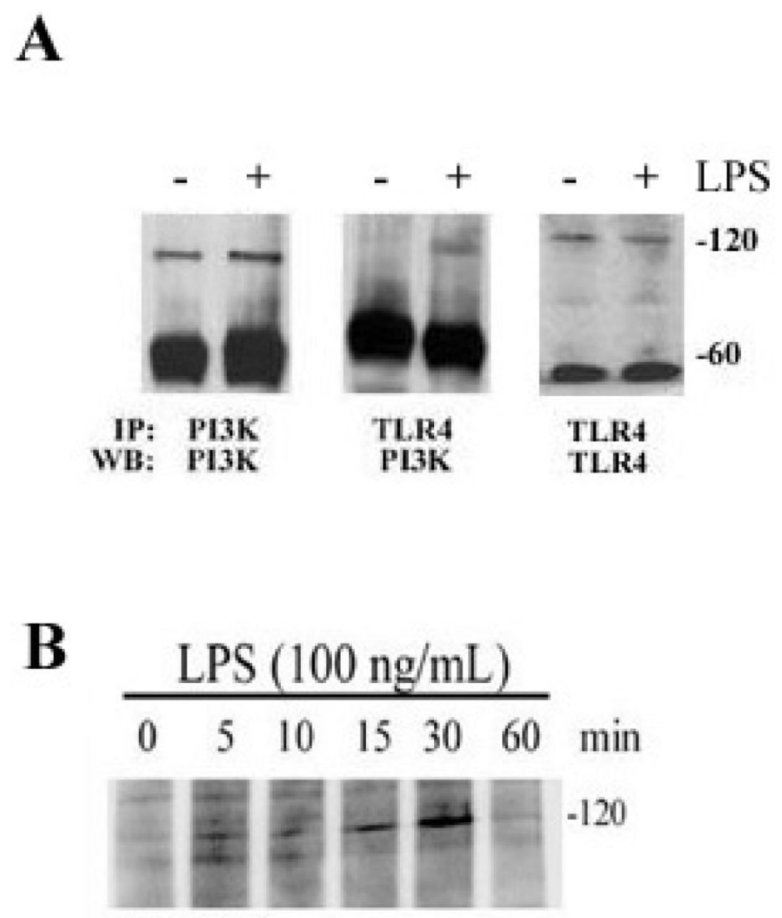

IP: TLR4

C

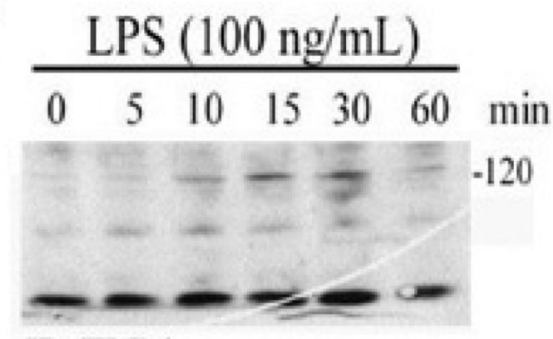

IP: TLR4

WB: phosph-Tyr

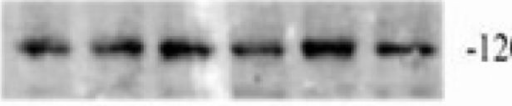

WB:TLR4

Figure 4. TLR4 Phosphorylation and interaction with PI3K following LPS exposure (A) RAW 264.7 macrophages were stimulated with $100 \mathrm{ng} / \mathrm{mL}$ LPS for $30 \mathrm{~min}$. Immunoprecipitates were separated by $12 \%$ SDS-PAGE and Western blotting was performed using antibodies against p85 PI3 kinase or TLR4. (B) RAW 264.7 macrophages were labeled in vitro with ${ }^{32} \mathrm{P}$ for $60 \mathrm{~min}$ and were stimulated with $100 \mathrm{ng} / \mathrm{mL}$ LPS for $0,5,10,15,30$ and $60 \mathrm{~min}$. Cell lysates were immunoprecipitated using anti-TLR4 antibody and separated by SDS-PAGE to evaluate phophorylation of the TLR4. Phosphorylation was visualized by autoradiagraphy. Immunoprecipitates were also immunoblotted using anti-phospho-tyrosine antibody (1:1000, Chemicon). (C) Cell lysates were separated by SDS-PAGE and immunoblotted using anti-TLR4 antibodies. 


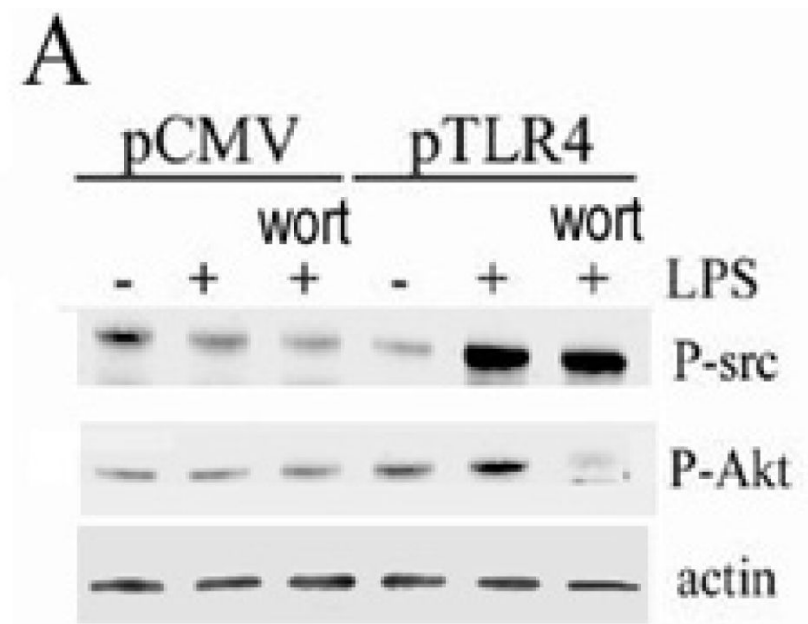

B
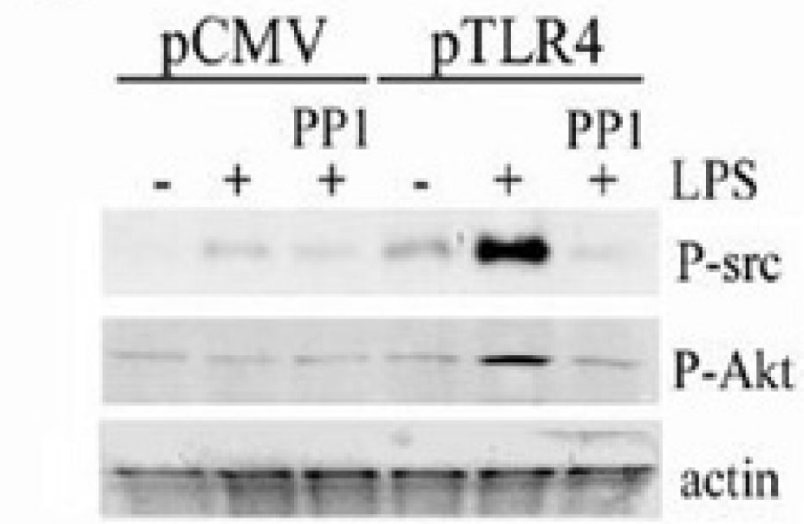

$C^{1}$

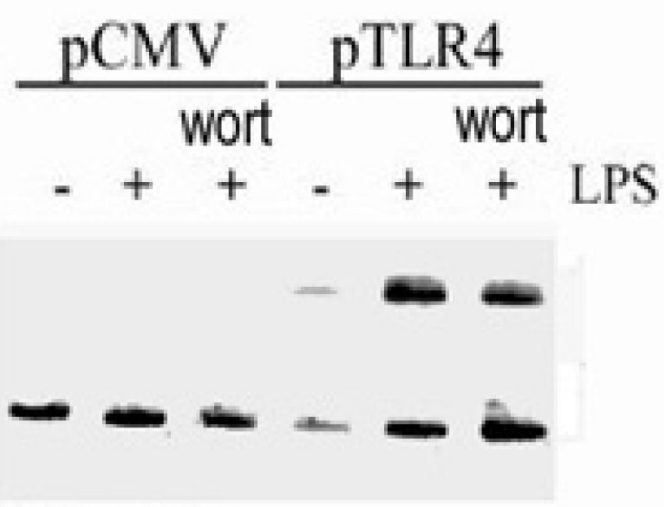

D

IP: TLR4

WB: P-tyr

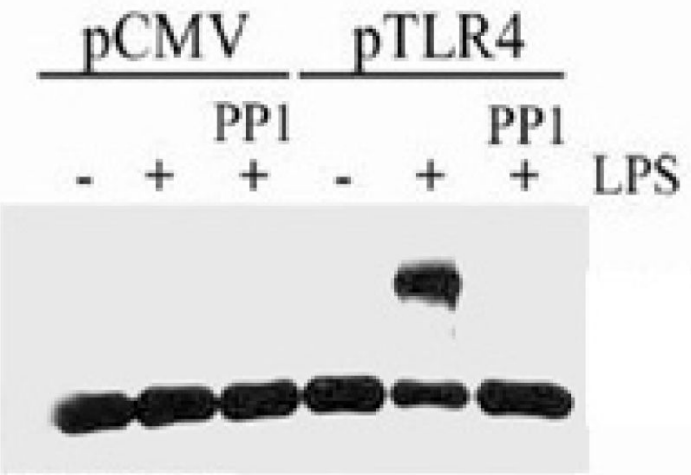

IP: TLR4

WB: P-tyr

Figure 5. src kinase is involved in the phosphorylation of TLR4 overexpressed in CHO-CD14 cells Chinese hamster ovary cells stably expressing CD14 were transiently transfected with either control pCMV or pCMV-hTLR4 (pTLR4). Twenty-four hours later, cells were stimulated with LPS (100ng/ml) in the presence of either (A and C) wortmannin (100nM) or (B and D) PP1 $(5 \mathrm{nM})$. Thirty minutes after stimulation, cell lysates were collected, separated by SDS-PAGE and immunoblotted against phospho-src kinase, phospho-AKT and actin. Cell lysates were immunoprecipitated using antibodies against human TLR4 (C and D). Immunoprecipitates were separated by SDS-PAGE and immunoblotted using antibodies against phospho-Tyr. 